\title{
SOLVABILITY AND NUMERICAL SOLUTIONS OF SYSTEMS OF NONLINEAR VOLTERRA INTEGRAL EQUATIONS OF THE FIRST KIND WITH PIECEWISE CONTINUOUS KERNELS
}

I.R. Muftahov, Irkutsk National Research Technical University, Irkutsk, Russian Federation, contact.dns@gmail.com

D.N. Sidorov, Melentiev Energy Systems Institute, Siberian Branch of Russian Academy of Sciences; Irkutsk National Research Technical University; Irkutsk State University, Irkutsk, Russian Federation, contact.dns@gmail.com

The existence theorem for systems of nonlinear Volterra integral equations kernels of the first kind with piecewise continuous is proved. Such equations model evolving dynamical systems. A numerical method for solving nonlinear Volterra integral equations of the first kind with piecewise continuous kernels is proposed using midpoint quadrature rule. Also numerical method for solution of systems of linear Volterra equations of the first kind is described. The examples demonstrate efficiency of proposed algorithms. The accuracy of proposed numerical methods is $\mathcal{O}\left(N^{-1}\right)$.

Keywords: Volterra integral equations; discontinuous kernel; ill-posed problem; evolving dynamical systems; quadrature; Dekker - Brent method.

1. Problem Statement and Existence Theorem. In this paper we study systems of nonlinear Volterra integral equations of the first kind with piecewise continuous kernels using our previous results $[1,2,3,5]$, where theory of linear scalar Volterra integral equations of the first kind with piecewise continuous kernels have been addressed.

Consider the following system of nonlinear Volterra equations of the first kind

$$
\int_{0}^{t} K(t, s, x(s)) d s=f(t), 0 \leqslant s \leqslant t \leqslant T, f(0)=0
$$

We make the following assumptions:

A) vector-function $K(t, s, x(s))$ is defined for $-\infty<x<\infty, 0 \leqslant s \leqslant t \leqslant T$ and has a discontinuities of the first kind at the curves $s=\alpha_{i}(t), i=1, \ldots, n-1$, i. e.

$$
K(t, s, x(s))=\left\{\begin{array}{c}
K_{1}(t, s) G_{1}(s, x(s)), t, s \in D_{1}, \\
\ldots \ldots \ldots \cdots \\
K_{n}(t, s) G_{n}(s, x(s)), t, s \in D_{n}
\end{array}\right.
$$

where $D_{i}=\left\{t, s \mid \alpha_{i-1}(t)<s<\alpha_{i}(t)\right\}, i=1, \ldots, n, a_{0}(t)=0, a_{n}(t) \equiv t, f(t)=$ $\left(f_{1}(t), \ldots, f_{m}(t)\right)^{\prime}, x(t)=\left(x_{1}(t), \ldots, x_{m}(t)\right)^{\prime}, m \times m$ matrices $K_{i}$ are defined, continuous and have continuous derivatives with respect to $t$ in the corresponding domains $D_{i}$, $f_{j}(t), j=1, \ldots, m$, and $\alpha_{i}(t), i=1, \ldots, n-1$ have continuous derivatives, $0<\alpha_{1}^{\prime}(0) \leqslant$ $\ldots \leqslant \alpha_{n-1}^{\prime}(0)<1, f_{j}(0)=0, \alpha_{i}(0)=0,0<\alpha_{1}(t)<\alpha_{2}(t)<\ldots<\alpha_{n-1}(t)<t$ for $t \in(0, T]$

B) matrices $K_{i}, i=1, \ldots, n$ have continuously differentiable with respect to $t$ continuation into compact $\{0 \leqslant s \leqslant t \leqslant T\}$. 
For the theory of systems of linear integral equations with piecewise continuous kernels readers may refer to monograph [5]. The objective of this paper is to generalize this theory on nonlinear case and suggest algorithm for numerical solution for such systems.

It is to be noted that Volterra equations with piecewise continuous kernels are employed in energetics and in other fields for evolving dynamical systems modeling. Here readers may refer to bibliography in $[2,4]$.

Let us first formulate the sufficient conditions for existence and uniqueness of the solution of system (1).

Theorem 1. Let conditions $A$ ) and $B$ ) be fulfilled for $0 \leqslant s \leqslant t \leqslant T$. Let Lipchitz condition $\left\|G_{i}\left(s, x_{1}(s)\right)-G_{i}\left(s, x_{2}(s)\right)-\left(x_{1}(s)-x_{2}(s)\right)\right\| \leqslant q_{i}\left\|x_{1}-x_{2}\right\|, \forall x_{1}, x_{2} \in \mathbb{R}^{n}$, be also fulfilled and $q_{n}+\sum_{i=1}^{n-1} \alpha_{i}^{\prime}(0)\left\|K_{n}(0,0)^{-1}\left(K_{i}(0,0)-K_{i+1}(0,0)\right)\right\|\left(1+q_{i}\right)<1$. Then $\exists \tau>0$ such that system (1) has unique local solution in $\mathcal{C}_{[0, \tau]}$. Moreover, if $\min _{\tau \leqslant t \leqslant T}(t-$ $\left.\alpha_{n-1}(t)\right)=h>0$ then such local solution can be continuously extended to the whole domain $[\tau, T]$ using combination of the method of steps and successive approximations.

Proof of this theorem is similar to the proof of Theorem 3.2 in [2] using the Lipchitz condition.

2. Numerical Solution. In this section we construct an algorithm based on of the midpoint quadrature for numerical solution of nonlinear Volterra integral equations (1). We also included the numerical examples to demonstrate the efficiency of the proposed scheme.

For sake of clarity we first consider the scalar case. To construct a numerical solution of equation (1) on the interval $[0, T]$ introduce the mesh (not necessarily uniform)

$$
0=t_{0}<t_{1}<t_{2}<\ldots<t_{N}=T, \quad h=\max _{i=1, N}\left(t_{i}-t_{i-1}\right)=\mathcal{O}\left(N^{-1}\right) .
$$

Following our paper [1] we search an approximate solution of equation (1) as following piecewise constant function

$$
x_{N}(t)=\sum_{i=1}^{N} x_{i} \delta_{i}(t), t \in(0, T], \delta_{i}(t)= \begin{cases}1, & \text { for } t \in \Delta_{i} \\ 0, & \text { for } t \notin \Delta_{i}\end{cases}
$$

with undetermined yet coefficients $x_{i}, i=\overline{1, N}$.

In order to find $x_{0}$ let us differentiate both sides of equation (1) with respect to $t$

$$
\begin{gathered}
f^{\prime}(t)=\sum_{i=1}^{n}\left(\int_{\alpha_{i-1}(t)}^{\alpha_{i}(t)} \frac{\partial K_{i}(t, s)}{\partial t} G_{i}(s, x(s)) d s+\right. \\
\left.+\alpha_{i}^{\prime}(t) K_{i}\left(t, \alpha_{i}(t)\right) G_{i}\left(\alpha_{i}(t), x\left(\alpha_{i}(t)\right)\right)-\alpha_{i-1}^{\prime}(t) K_{i}\left(t, \alpha_{i-1}(t)\right) G_{i}\left(\alpha_{i-1}(t), x\left(\alpha_{i-1}(t)\right)\right)\right) .
\end{gathered}
$$

Then $\quad f^{\prime}(0)=\sum_{i=1}^{n}\left(\alpha_{i}^{\prime}(0) K_{i}(0,0) G_{i}\left(0, x_{0}\right)-\alpha_{i-1}^{\prime}(0) K_{i}(0,0) G_{i}\left(0, x_{0}\right)\right)$. The desired coefficient $x_{0}$ is included in nonlinearly in the right hand side. We use the Van Wijngaarden 
- Dekker - Brent method to find this coefficient $x_{0}$ (see e.g. [6]). Below we shall use the notation $f_{k}=f\left(t_{k}\right), k=1, \ldots, N$, and $v_{i j}$ denotes the index of mesh's segment (2) that contains the value $\alpha_{i}\left(t_{j}\right)$, i.e. $\alpha_{i}\left(t_{j}\right) \in \Delta_{v_{i j}}$. Obviously $v_{i j}<j$ for $i=\overline{0, n-1}, j=\overline{1, N}$. Let us now assume that the coefficients $x_{0}, x_{1}, \ldots, x_{k-1}$ of approximate solution are known. Equation (1) in the knot $t=t_{k}$ is $\sum_{i=1}^{n} \int_{\alpha_{i-1}\left(t_{k}\right)}^{\alpha_{i}\left(t_{k}\right)} K_{i}\left(t_{k}, s\right) G_{i}(s, x(s)) d s=f_{k}$, and it can be presented as $I_{1}\left(t_{k}\right)+I_{2}\left(t_{k}\right)+\cdots+I_{n}\left(t_{k}\right)=f_{k}$, where

$$
\begin{gathered}
I_{1}\left(t_{k}\right)=\sum_{j=1}^{v_{1, k}-1} \int_{t_{j-1}}^{t_{j}} K_{1}\left(t_{k}, s\right) G_{1}(s, x(s)) d s+\int_{t_{v_{1, k}}-1}^{\alpha_{1}\left(t_{k}\right)} K_{1}\left(t_{k}, s\right) G_{1}(s, x(s)) d s, \\
I_{n}\left(t_{k}\right)=\int_{\alpha_{n-1}\left(t_{k}\right)}^{t_{v_{n-1, k}}} K_{n}\left(t_{k}, s\right) G_{n}(s, x(s)) d s+\sum_{j=v_{n-1, k}+1}^{k} \int_{t_{j-1}}^{t_{j}} K_{n}\left(t_{k}, s\right) G_{n}(s, x(s)) d s .
\end{gathered}
$$

1. If $v_{p-1, k} \neq v_{p, k}, p=2, \ldots, n-1$ then

$$
\begin{gathered}
I_{p}\left(t_{k}\right)=\int_{\alpha_{p-1}\left(t_{k}\right)}^{t_{v_{p-1, k}}} K_{p}\left(t_{k}, s\right) G_{p}(s, x(s)) d s+\sum_{j=v_{p-1, k}+1}^{v_{p, k}-1} \int_{t_{j-1}}^{t_{j}} K_{p}\left(t_{k}, s\right) G_{p}(s, x(s)) d s+ \\
+\int_{t_{v_{p, k}-1}}^{\alpha_{p}\left(t_{k}\right)} K_{p}\left(t_{k}, s\right) G_{p}(s, x(s)) d s
\end{gathered}
$$

2. If $v_{p-1, k}=v_{p, k}, p=2, \ldots, n-1$ then $I_{p}\left(t_{k}\right)=\int_{\alpha_{p-1}\left(t_{k}\right)}^{\alpha_{p}\left(t_{k}\right)} K_{p}\left(t_{k}, s\right) G_{p}(s, x(s)) d s$.

It is to be noted that the number of terms in each row of this formula depends on array $v_{i j}$, which can be determined based on input data: functions $\alpha_{i}(t), i=\overline{1, n-1}$ and fixed (based on concrete $N$ ) mesh.

Each integral in the last equation can be approximated using the midpoint quadrature rule, i.e.

$$
\int_{t_{m}}^{\alpha_{p}\left(t_{k}\right)} K_{p}\left(t_{k}, s\right) G_{p}(s, x(s)) d s \approx\left(\alpha_{p}\left(t_{k}\right)-t_{m}\right) K_{p}\left(t_{k}, s_{k}\right) G_{p}\left(s_{k}, x_{N}\left(s_{k}\right)\right),
$$

where $m=v_{p, k}-1, s_{k}=\frac{\alpha_{p}\left(t_{k}\right)+t_{m}}{2}$. Moreover, on the intervals where the desired function is determined, we select $x_{N}(t)$ (i.e. $t \leqslant t_{k-1}$ ). On the rest of the intervals the unknown value $x_{k}$ appears in the last few terms. We determine the number of such terms using the analysis of array $v_{i j}$. In order to find $x_{k}$ we use the Van Wijngaarden - Dekker Brent method and proceed with computation of $x_{k+1}$. The accuracy of proposed method is $\varepsilon=\max _{0 \leqslant i \leqslant N}\left|\bar{x}\left(t_{i}\right)-x_{N}\left(t_{i}\right)\right|$, where $\bar{x}\left(t_{i}\right)$ and $x_{N}\left(t_{i}\right)$ are exact and approximate solution in the point $t_{i}$ correspondingly. The method has order of $\mathcal{O}\left(\frac{1}{N}\right)$.

Let us now consider the numerical solution of the following system of linear integral equations

$$
\int_{0}^{t} K(t, s) x(s) d s=f(t), 0 \leqslant s \leqslant t \leqslant T, f(0)=0,
$$


where $m \times m$ matrix kernel $K(t, s)$ on the compact $0 \leqslant s \leqslant t \leqslant T$ has 1st kind discontinuities on the curves $s=\alpha_{i}(t), i=1, \ldots, n-1$.

An approximate solution of system (4) is searched again as a piecewise constant function $x_{N}(t)=\left(x_{1}^{(N)}(t), \ldots, x_{m}^{(N)}(t)\right)^{\prime}$, where

$$
x_{i}^{(N)}(t)=\sum_{j=1}^{N} x_{i, j}^{(N)} \delta_{j}(t), t \in(0, T], \delta_{j}(t)= \begin{cases}1, & \text { for } t \in \Delta_{j} \\ 0, & \text { for } t \notin \Delta_{j} .\end{cases}
$$

with coefficients $x_{i, j}^{(N)}, i=\overline{1, m}, j=\overline{1, N}$.

Let us introduce the following mesh of knots

$$
0=t_{0}<t_{1}<t_{2}<\ldots<t_{N}=T, h=\max _{i=1, N}\left(t_{i}-t_{i-1}\right)=\mathcal{O}\left(N^{-1}\right)
$$

for numerical solution of system (4) on the interval $[0, T]$. Make the following notation $f_{i, k}=f_{i}\left(t_{k}\right), k=1, \ldots, N, K^{(i, p)}\left(t_{k}, s\right)$ is $(i, p)$-th entry of matrix $K\left(t_{k}, s\right), i=\overline{1, m}, p=$ $\overline{1, m}$. This is the function with 1 st kind discontinuities on curves $\alpha_{1}\left(t_{k}\right)<\alpha_{2}\left(t_{k}\right)<\ldots$ $<\alpha_{n-1}\left(t_{k}\right)$, i.e.

$$
\int_{0}^{t_{k}} K^{(i, p)}\left(t_{k}, s\right) x_{p}(s) d s=\sum_{q=1}^{n} \int_{\alpha_{q-1}\left(t_{k}\right)}^{\alpha_{q}\left(t_{k}\right)} K_{q}^{(i, p)}\left(t_{k}, s\right) x_{p}(s) d s .
$$

Let us differentiate both sides of equation (4) with respect to $t$ in order to find $x_{N}(0)$

$$
\begin{gathered}
f_{i}^{\prime}(t)=\sum_{p=1}^{m} \sum_{q=1}^{n}\left(\int_{\alpha_{q-1}(t)}^{\alpha_{q}(t)} \frac{\partial K_{q}^{(i, p)}(t, s)}{\partial t} x_{p}(s) d s+\right. \\
\left.+\alpha_{i}^{\prime}(t) K_{q}^{(i, p)}\left(t, \alpha_{i}(t)\right) x_{p}\left(\alpha_{i}(t)\right)-\alpha_{i-1}^{\prime}(t) K_{q}^{(i, p)}\left(t, \alpha_{i-1}(t)\right) x_{p}\left(\alpha_{i-1}(t)\right)\right) .
\end{gathered}
$$

Since all the components $x_{p}(0)$ of the desired vector $x(0)$ can be assumed constant, we gain the following system

$$
f_{i}^{\prime}(0)=\sum_{q=1}^{n}\left(K_{q}^{(i, p)}(0,0)\left(\alpha_{q}^{\prime}(0)-\alpha_{q-1}^{\prime}(0)\right)\right) \sum_{p=1}^{m} x_{p, 0}^{(N)}(0) .
$$

Solve the system of linear algebraic equations (8) and determine $x_{p, 0}^{(N)}(0)$ for $p=\overline{1, m}$.

Let coefficients $x_{p, 0}^{(N)}, x_{p, 1}^{(N)}, \ldots, x_{p, k-1}^{(N)}$ be known. Rewrite system (4) in the point $t=t_{k}$. For $i$ th row we have

$$
\sum_{p=1}^{m} \int_{t_{k-1}}^{t_{k}} K^{(i, p)}\left(t_{k}, s\right) x_{p}(s) d s=f_{i}\left(t_{k}\right)-\sum_{p=1}^{m} \int_{t_{0}}^{t_{k-1}} K^{(i, p)}\left(t_{k}, s\right) x_{p}(s) d s .
$$

Taking into account (5) we obtain

$$
\sum_{p=1}^{m} \int_{t_{k-1}}^{t_{k}} K^{(i, p)}\left(t_{k}, s\right) d s x_{p, k}^{(N)}=f_{i, k}-\sum_{p=1}^{m} \sum_{j=1}^{k-1} \int_{t_{j-1}}^{t_{j}} K^{(i, p)}\left(t_{k}, s\right) d s x_{p, j}^{(N)} .
$$


Finally taking into account (7) we obtain the following system of linear algebraic equations

$$
\sum_{p=1}^{m} \sum_{q=1}^{n} \int_{\alpha_{q-1}\left(t_{k}\right)}^{\alpha_{q}\left(t_{k}\right)} K_{q}^{(i, p)}\left(t_{k}, s\right) d s x_{p, k}^{(N)}=f_{i, k}-\sum_{p=1}^{m} \sum_{j=1}^{k-1} \sum_{q=1}^{n} \int_{\alpha_{q-1}\left(t_{k}\right)}^{\alpha_{q}\left(t_{k}\right)} K_{q}^{(i, p)}\left(t_{k}, s\right) d s x_{p, j}^{(N)},
$$

which is solved to determine coefficients $x_{p, k}^{(N)}$ for $p=\overline{1, m}$.

\section{Numerical Examples}

1.

$$
\begin{gathered}
\int_{0}^{t / 8}(1+t-s) \sin x(s) d s+\int_{t / 8}^{t / 4}(t-1) 2 \sin x(s) d s+\int_{t / 4}^{t}(-1)\left(\sin ^{2} x(s)+1\right) d s= \\
=-2 \frac{1}{8} t+\frac{7 t}{8} \cos \frac{t}{8}+(1+2 t) \sin \frac{t}{8}-2 t \sin \frac{t}{4}-\frac{1}{4} \sin \frac{t}{2}+\frac{1}{4} \sin 2 t, t \in[0,2] .
\end{gathered}
$$

The exact solution is $\bar{x}(t)=t$. Tab. 1 demonstrates errors $\varepsilon$ for various step sizes.

Table 1

Errors for various $h$ (example of nonlinear equation)

\begin{tabular}{|c|c|c|c|c|c|c|c|}
\hline$h$ & $1 / 32$ & $1 / 64$ & $1 / 128$ & $1 / 256$ & $1 / 512$ & $1 / 1024$ & $1 / 2048$ \\
\hline$\varepsilon$ & 0,345567 & 0,178316 & 0,091509 & 0,047107 & 0,023892 & 0,012031 & 0,006037 \\
\hline
\end{tabular}

2.

$$
\begin{aligned}
& \int_{0}^{t / 4}\left(\begin{array}{cc}
2+t s, & 1-t s \\
1+t+s, & 1-t s
\end{array}\right) \cdot\left(\begin{array}{l}
x_{1}(s) \\
x_{2}(s)
\end{array}\right) d s+\int_{t / 4}^{t / 2}\left(\begin{array}{cc}
1+t+s, & t+s \\
\frac{s}{1+t}, & t+s
\end{array}\right) \cdot\left(\begin{array}{l}
x_{1}(s) \\
x_{2}(s)
\end{array}\right) d s+ \\
& +\int_{t / 2}^{t}\left(\begin{array}{cc}
1+t+s, & -1 \\
1, & \frac{-1}{1+t}
\end{array}\right) \cdot\left(\begin{array}{l}
x_{1}(s) \\
x_{2}(s)
\end{array}\right) d s=\left(\begin{array}{c}
\frac{t^{6}}{40960}+\frac{1129 t^{5}}{20480}+\frac{2027 t^{4}}{24576}-\frac{55 t^{3}}{192} \\
\frac{1}{t+1} \cdot\left(\frac{-17 t^{6}}{20480}+\frac{4943 t^{5}}{61440}+\frac{2107 t^{4}}{24576}-\frac{55 t^{3}}{192}\right)
\end{array}\right),
\end{aligned}
$$

where exact solution is $\bar{x}(t)=\left(\begin{array}{c}t^{3} / 8 \\ t^{2}\end{array}\right), t \in[0,2]$. Tab. 2 demonstrates errors $\varepsilon_{i}=$ $\max _{0 \leqslant j \leqslant N}\left|\bar{x}_{i}\left(t_{j}\right)-x_{i}^{(N)}\left(t_{j}\right)\right|, i=1,2$, where $\bar{x}_{i}\left(t_{j}\right)$ and $x_{i}^{(N)}\left(t_{j}\right)$ are corresponding exact and computed solutions in the knots $t_{j}$ for various step sizes.

Table 2

Errors for various $h$ (example of systems)

\begin{tabular}{|c|c|c|c|c|c|c|c|}
\hline$h$ & $1 / 32$ & $1 / 64$ & $1 / 128$ & $1 / 256$ & $1 / 512$ & $1 / 1024$ & $1 / 2048$ \\
\hline$\varepsilon_{1}$ & 0,054205 & 0,028218 & 0,014392 & 0,007267 & 0,003652 & 0,001830 & 0,000916 \\
\hline$\varepsilon_{2}$ & 0,127717 & 0,064389 & 0,032327 & 0,016196 & 0,008106 & 0,004055 & 0,002028 \\
\hline
\end{tabular}


Conslusion. In this brief paper we continue our studies of Volterra integral equations of the first kind with discontinuous kernels [1-5]. We further develop the numerical methods [1] and suggest methods for solutions of systems of such linear equations and nonlinear equations. The midpoint quadrature rule is employed and the error order is $\mathcal{O}(1 / N)$. The numerical method is evaluated on synthetic data and demonstrated uniform $T$-convergence [7] of the sequence $\left\{x_{N}\left(t_{i}\right)\right\}_{i=1}^{N}$ to solution $\bar{x}(t)$ with rate $\mathcal{O}(1 / N)$.

Acknowledgment. The authors are thankfull to Dr. A.N. Tynda for valuable comments and discussions of the results presented in this article. The second author is partly supported by the International science and technology cooperation program of China and Russia under Grant No. 2015DFA70580.

\title{
References
}

1. Sidorov D.N., Tynda A.N., Muftahov I.R. Numerical Solution of Volterra Integral Equations of the First Kind with Piecewise Continuous Kernel. Bulletin of the South Ural State University. Series: Mathematical Modelling, Programming and Computer Software, 2014, vol. 7, no. 3, pp. 107-115. (in Russian) DOI: 10.14529/mmp140311

2. Sidorov D.N. Integral Dynamical Models: Singularities, Signals and Control. World Scientific Series on Nonlinear Science, ser. A, vol. 87, Singapore, World Sc. Publ., 2015. 260 p.

3. Sidorov D.N. Solution to the Volterra Integral Equations of the First Kind with Discontinuous Kernels. Bulletin of the South Ural State University. Series: Mathematical Modelling, Programming and Computer Software, 2012, no. 18 (277), pp. 44-52. (in Russian)

4. Markova E.V., Sidorov D.N. On One Integral Volterra Model of Developing Dynamical Systems. Automation and Remote Control, 2014, vol. 75, no 3, pp. 413-421. DOI: $10.1134 /$ S0005117914030011

5. Sidorov D.N. Solution to Systems of Volterra Integral Equations of the First Kind with Piecewise Continuous Kernels. Russian Mathematics, 2013, vol. 57, pp. 62-72. DOI: $10.3103 /$ S1066369X13010064

6. Brent R.P. An Algorithm with Guaranteed Convergence for Finding a Zero of a Function. The Computer Journal, 1971, vol. 14, no 4, pp. 422-425. DOI: 10.1093/comjnl/14.4.422

7. Trenogin V.A. Funktsional'nyy analiz [Functional Analysis]. Moscow, Fizmatlit, 2002. (in Russian)

\section{РАЗРЕШИМОСТЬ И АЛГОРИТМ ЧИСЛЕННОГО РЕШЕНИЯ СИСТЕМЫ НЕЛИНЕЙНЫХ ИНТЕГРАЛЬНЫХ УРАВНЕНИЙ ВОЛЬТЕРРА І РОДА С КУСОЧНО-НЕПРЕРЫВНЫМИ ЯДРАМИ}

\author{
И.Р. Муфтахов, Д.Н. Сидоров
}

Доказана теорема существования и разработан численный метод решения систем нелинейньх интегральных уравнений Вольтерра первого рода с кусочнонепрерывными ядрами, возникающих в моделировании развивающихся динамических 
систем. В качестве квадратурной формулы используется метод средних прямоугольников, при этом решение ищется в виде кусочно-постоянной функции. Для решения нелинейного уравнения использован комбинированный метод Дэккера и Брэнта. Приведены результаты расчетов для скалярного нелинейного уравнения и для систем линейных уравнений. Точность предложенных численных методов $\mathcal{O}(1 / N)$.

Ключевые слова: интегральные уравнения Вольтерра I рода; развивающиеся системы; разрывное ядро; нелинейные системы; численные методы; метод Дэккера $и$ Брэнта; квадратурной формулы.

\section{Литература}

1. Сидоров, Д.Н. Численное решение интегральных уравнений Вольтерра I рода с кусочнонепрерывными ядрами / Д.Н. Сидоров, А.Н. Тында, И.Р. Муфтахов // Вестник ЮУрГУ. Серия: Математическое моделирование и программирование. - 2014. - Т. 7, № 3. C. $107-115$.

2. Sidorov, D. Integral Dynamical Models: Singularities, Signals and Control. World Scientific Series on Nonlinear Science Series A: V. 87 / D. Sidorov. - Singapore: World Sc. Publ., 2015. - 260 p.

3. Сидоров, Д.Н. О семействах решений интегральных уравнений Вольтерры первого рода с разрывными ядрами / Д.Н. Сидоров // Вестник ЮУрГУ. Серия: Математическое моделирование и программирование. - 2012. - №18 (277), вып. 12. - С. 44-52.

4. Markova, E.V. On One Integral Volterra Model of Developing Dynamical Systems / E.V. Markova, D.N. Sidorov // Automation and Remote Control. - 2014. - V. 75, № 3. - P. 413-421.

5. Sidorov, D.N. Solution to Systems of Volterra Integral Equations of the First Kind with Piecewise Continuous Kernels / D.N. Sidorov // Russian Mathematics. - 2013. - V. 57. P. $62-72$.

6. Brent, R.P. An Algorithm with Guaranteed Convergence for Finding a Zero of a Function / R.P. Brent // The Computer Journal. - 1971. - V. 14, № 4. - P. 422-425.

7. Треногин, В.А. Функциональный анализ / В.А. Треногин. - М: Физматлит, 2002.

Ильдар Ринатович Муфтахов, аспирант кафедры «Вычислительная техника», Иркутский национальный исследовательский технический университет (г. Иркутск, Российская Федерация).

Денис Николаевич Сидоров, доктор физико-математических наук, профессор кафедры «Вычислительная техника», Иркутский национальный исследовательский технический университет; Иркутский государственный университет, Институт систем энергетики им. Л.А. Мелентьева СО РАН (г. Иркутск, Российская Федарация), contact.dns@gmail.com.

Поступила в редакцию 27 ноября 2015 г. 